\title{
A PROBLEMÁTICA DO BULLYING NO CONTEXTO ESCOLAR: PROPOSTA DE APLICATIVO COMO FERRAMENTA DE RESILIÊNCIA
}

\author{
THE PROBLEM OF BULLYING IN THE SCHOOL CONTEXT: PROPOSAL OF APPLICATION \\ AS A RESILIENCE
}

\section{LA PROBLEMÁTICA DEL BULLYING EN EL CONTEXTO ESCOLAR: PROPUESTA DE APLICACIÓN COMO HERRAMIENTA DE RESILIENCIA}

\author{
Carla Moreira Graça Mello1 \\ Patrícia Osório Pereira ${ }^{2}$ \\ Denise Celeste Godoy de Andrade Rodrigues ${ }^{3}$
}

\begin{abstract}
RESUMO
O bullying é um problema de saúde pública que causa prejuízos físicos, sociais, afetivos e cognitivos, que devido ao espantoso crescimento se tornou um tema emergente. 0 presente trabalho tem como objetivos estudar o fenômeno do bullying e propor a criação de um aplicativo que visa aumentar a resiliência ao bullying. Trata-se de uma Revisão Integrativa, realizada na Base de dados do periódico CAPES, nos últimos cinco anos em duas categorias, que correspondem ao ano de aprovação da Lei 13.185 de 6 de novembro de 2015, que instituiu o programa de Combate à Intimidação Sistemática (bullying) e na terceira categoria nos últimos sete anos. Os descritores foram, Bullying and Depressão, Resiliência and Interação Social e Bullying and Intervenções. Após refinamento foram selecionados 20 artigos. As três categorias identificadas foram: Bullying um problema de Saúde Mental (7 artigos); Caminhos para resiliência ao bullying (5 artigos); Propostas de intervenção do bullying (8 artigos). A pesquisa revelou a importância de novas intervenções de combate, prevenção e de resiliência ao bullying, levando a criação do aplicativo "Humanizar" no intuito de auxiliar a resiliência ao bullying.
\end{abstract}

PALAVRAS-CHAVE: Resiliência. Bullying. Humanização.

\section{ABSTRACT}

Bullying is a public health problem that causes physical, social, affective and cognitive impairments, which due to the astonishing growth has become an emerging issue. The present work aims to study the phenomenon of bullying and propose the creation of an application that aims to increase resilience to bullying. This is an Integrative Review, carried out in the CAPES Journal Database, in the last five years in two categories, corresponding to the year of approval of Law 13,185 of November 6, 2015, which established the Program for Combating Systematic Intimidation (bullying) and third category in the last seven years. The descriptors were, Bullying and Depression, Resilience and Social Interaction and Bullying and Interventions. After refinement, 19 articles were selected. The three categories identified were: Bullying a Mental Health problem (7 articles); Paths to resilience to bullying (5 articles); Bullying intervention proposals (7 articles). The research revealed the importance of new interventions in combat, prevention and resilience to bullying, leading to the creation of the application "Humanizar" in order to help resilience to bullying.

KEYWORDS: Resilience, bullying, humanization.

\footnotetext{
${ }^{1}$ Mestranda do Programa de Pós-Graduação em Ensino em Ciências da Saúde e do Meio Ambiente do Centro Universitário de Volta Redonda (UniFOA).

2 Mestranda do Programa de Pós-Graduação em Ensino em Ciências da Saúde e do Meio Ambiente do Centro Universitário de Volta Redonda (UniFOA).

${ }^{3}$ Engenheira Química, com doutorado em Ciências pela USP. Professora Associada da Universidade do Estado do Rio de Janeiro (UERJ). Orientadora do Programa de Pós-Graduação em Ensino em Ciências da Saúde e do Meio Ambiente do Centro Universitário de Volta Redonda (UniFOA).
} 


\section{RESUMEN}

El bullying es un problema de salud pública que causa perjuicios físicos, sociales, afectivos y cognitivos, que debido al espantoso crecimiento se ha convertido en un tema emergente. El presente trabajo tiene como objetivos estudiar el fenómeno del bullying y proponer la creación de una aplicación que busca aumentar la resiliencia al bullying. Se trata de una Revisión Integrativa, realizada en la Base de datos del periódico CAPES, en los últimos cinco años en dos categorías, que corresponden al año de aprobación de la Ley 13.185 de 6 de noviembre de 2015, que instituyó el programa de Combate a la Intimidación Sistemática (bullying) y en la tercera categoría en los últimos siete años. Los descriptores fueron, Bullying y Depresión, Resiliencia e Interacción Social y Bullying e Intervenciones. Después del refinamiento se seleccionaron 19 artículos. Las tres categorías identificadas fueron: Bullying un problema de Salud Mental (7 artículos); Caminos para resiliencia al bullying (5 artículos); Propuestas de intervención del bullying (7 artículos). La investigación reveló la importancia de nuevas intervenciones de combate, prevención y de resiliencia al bullying, llevando la creación de la aplicación Humanizar con el fin de auxiliar la resiliencia al bullying.

PALABRAS CLAVE: Resiliencia, bullying, humanización.

\section{INTRODUÇÃO}

Diversos estudos têm relatado o aumento da violência na sociedade, sendo a violência escolar um reflexo desse processo, acarretando em comportamentos agressivos entre os estudantes e baixo rendimento escolar, muitas vezes associado ao bullying (LIRA, 2019, MIRANDA; LIMA, 2019, SILVA; OSIECKI, 2018, SILVA et al, 2018).

Madaloz e Ebling (2019) afirmam que embora o bullying seja um fenômeno antigo, somente na década de 70 a sociedade começou a se preocupar com sua prática e suas consequências. Os primeiros estudos sobre o tema ocorreram na Suécia, onde os resultados positivos das intervenções despertaram 0 interesse de novas pesquisas e de outros pesquisadores (OLIVEIRA, 2018).

uma pesquisa realizada em 2011 com 39 estudantes na faixa etária de 13 a 15 anos de uma escola pública do Distrito Federal, 16 haviam sofrido algum tipo de intimidação, agressão ou assédio (LIRA, 2019). Já Cavalcanti et al (2018) relata que uma pesquisa feita no Brasil em 2013 pelo Ministério da Saúde e pelo Instituto Brasileiro de Geografia e Estatística apontou que 7,2\% dos alunos revelaram que com frequência são vítimas de humilhações por provocadores.

O espantoso crescimento do bullying gera assimilações prejudiciais sobre si mesmo e sobre o convívio social, onde para obter espaço e lugar social a tática utilizada é a agressividade (OLIVEIRA et al, 2017).

No Brasil, a Lei 13.185 de 6 de novembro de 2015 instituiu o programa de Combate à Intimidação Sistemática (bullying), trazendo também uma definição formal a esse fenômeno (BRASIL, 2015).

Art. $1^{\circ}$ Fica instituído o Programa de Combate à Intimidação Sistemática (Bullying) em todo o território nacional.

$\S 1^{\circ}$ No contexto e para os fins desta Lei, considera-se intimidação sistemática (bullying) todo ato de violência física ou psicológica, intencional e repetitivo que ocorre sem motivação evidente, praticado por indivíduo ou grupo, contra uma ou mais pessoas, com o objetivo de intimidá-la ou agredi-la, causando dor e angústia à vítima, em uma relação de desequilíbrio de poder entre as partes envolvidas. 
Em 2018, o Congresso Nacional decretou a lei $n^{0}$ 13.663, de 14 de maio de 2018, alterando 0 art. 12 da Lei $n^{\circ}$ 9.394, de 20 de dezembro de 1996, para incluir a promoção de medidas de conscientização, de prevenção e de combate a todos os tipos de violência, especialmente a intimidação sistemática entre as incumbências dos estabelecimentos de ensino (BRASIL, 2018).

Art. $1^{\circ} \mathrm{O}$ caput do art. 12 da Lei $n^{0}$ 9.394, de 20 de dezembro de 1996, passa a vigorar acrescido dos seguintes incisos IX $\mathrm{e} X$ : Art.12...............................................................................IX - promover medidas de conscientização, de prevenção e de combate a todos os tipos de violência, especialmente a intimidação sistemática (bullying), no âmbito das escolas; $X$ - estabelecer ações destinadas a promover a cultura de paz nas escolas.

Mesmo com a Lei 13.663, ainda se verifica nas escolas falta de debate sobre o bullying, de estrutura ou organização na escola para prevenir e inibir essa prática (SILVA et al, 2018). Além disso, a violência na escola não tem diminuído, como constatado por Souza e Figueiredo (2018, p. 80):

\begin{abstract}
A pesquisa aqui apresentada indica que a violência não está diminuindo porque as suas principais origens - as relações de dominação social reproduzidas dentro da escola - não estão sendo transformadas em objeto de análise pedagógica, o que seria uma condição preliminar para que professores pesquisadores pudessem formular novos métodos educativos para envolver os estudantes em processos dialógicos de reflexão e transformação para a democratização da sociedade.
\end{abstract}

Sendo o bullying uma prática tão antiga e impregnada na cultura da competitividade e no contexto escolar, além das medidas preventivas, é necessário romper esse ciclo de violência e investir no desenvolvimento da resiliência ao mesmo. Ser resiliente significa aprender a lutar contra as adversidades de forma criativa e saudável.

Diante do exposto, o objetivo geral desse artigo é estudar o fenômeno do bullying e da resiliência. Como objetivo específico, criar um aplicativo como ferramenta de Resiliência ao Bullying. A relevância deste trabalho está na importância de buscar intervenções eficazes que reduzam os efeitos negativos do dessa prática nas escolas.

\title{
2. METODOLOGIA
}

Essa pesquisa é de cunho qualitativo, tendo sido empregada a revisão integrativa como ferramenta. A revisão integrativa é uma metodologia que permite combinar dados da literatura 
com o objetivo de auxiliar na compreensão de um determinado fenômeno, revisar conceitos, teorias e metodologias. (SOUZA; SILVA; CARVALHO, 2010). A busca foi realizada na Base de dados Periódicos CAPES com recorte temporal dos últimos cinco anos, que corresponde ao ano de aprovação da Lei 13.185 de 6 de novembro de 2015, que instituiu o programa de Combate à Intimidação Sistemática (bullying).

Os descritores e refinamentos utilizados foram:

1- Bullying and Depressão no título gerando 27 artigos. Os critérios de refinamento foram: de 2015 a 2018, totalizando 12 artigos, revisados por pares num total de 9 artigos. Foram excluídos dois artigos que não estavam em consonância com o objetivo deste artigo somando 7 artigos.

2- Resiliência and Interação Social no título, totalizando 18 artigos. Os critérios de refinamento foram: Revistas Psicologia e Saber Social, Revista de Educação Física, Estudos de Psicologia (Natal) Educação (UFSM) Dominio de las Ciencias totalizando 5 artigos. Neste indexador 0 período de tempo foi de 2013 a 2018, devido à relevância de dois artigos escritos nesta época.

3- Bullying and Intervenções gerando 104 arquivos. Os critérios de refinamento foram: o recorte temporal de 2015 a 2018 gerando 39 artigos, por tópico: bullying totalizando 13 artigos. Periódicos revisados por pares, totalizando 8 artigos.

\section{RESULTADOS E DISCUSSÃO}

Mediante os critérios de busca e refinamento descritos na metodologia, foram selecionados 19 artigos no total, que se encontram no Quadro 1. Na sequência foi realizada uma análise dos artigos selecionados e foram identificadas três categorias: Bullying um problema de Saúde Mental (artigos 1, 2, 3, 4, 5, 6 e 7); Caminhos para resiliência ao bullying (artigos 8, 9, 10, 11 e 12); Propostas de intervenção ao bullying (artigos 13, 14, 15, 16, 17, 18, 19 e 20).

QUADRO 1 - Distribuição dos estudos examinados, segundo o título/autores/ano de publicação, periódicos e contribuição da pesquisa

\begin{tabular}{|c|c|c|c|}
\hline n. & Título/Autor(es)/ Ano & Periódico & Contribuição da pesquisa \\
\hline 1 & $\begin{array}{l}\text { Bullying, vitimização por funcionários e } \\
\text { depressão: } \\
\text { Relações com o engajamento emocional }\end{array}$ & $\begin{array}{l}\text { Revista Brasileira de } \\
\text { Psicologia Escolar e } \\
\text { Educacional }\end{array}$ & $\begin{array}{l}\text { Investigar se a violência escolar e a } \\
\text { depressão podem interferir no } \\
\text { engajamento emocional escolar. }\end{array}$ \\
\hline
\end{tabular}




\begin{tabular}{|c|c|c|c|}
\hline & $\begin{array}{l}\text { escolar. } \\
\text { Jéssica Elena Valle. Ana Carina Stelko- } \\
\text { Pereira. Lucas Guimarães Cardoso de Sá. } \\
\text { Lúcia Cavalcanti de Albuquerque Williams, } \\
2015 .\end{array}$ & & \\
\hline 2 & $\begin{array}{l}\text { Vitimização e Percepção do Bullying: Relação } \\
\text { com a Sintomatologia Depressiva de } \\
\text { Adolescentes. } \\
\text { Jaqueline Gomes Cavalcanti. Maria da Penha } \\
\text { de Lima Coutinho. Adriele Vieira de Lima } \\
\text { Pinto. Karla Costa Silva, Emerson Araújo Do } \\
\text { Bú, } 2018 .\end{array}$ & $\begin{array}{l}\text { Revista de Psicologia } \\
\text { da IMED }\end{array}$ & $\begin{array}{l}\text { Conhecer a relação entre vitimização, } \\
\text { percepção acerca do bullying, e } \\
\text { sintomatologia depressiva no contexto de } \\
\text { adolescentes escolares. }\end{array}$ \\
\hline 3 & $\begin{array}{l}\text { Saúde do escolar: uma revisão integrativa } \\
\text { sobre família e bullying. Wanderlei Abadio de } \\
\text { Oliveira. Jorge Luiz da Silva. Julliane Messias } \\
\text { Cordeiro Sampaio. Marta Angélica lossi Silva, } \\
2017 \text {. }\end{array}$ & $\begin{array}{l}\text { Revista Ciência \& } \\
\text { Saúde Coletiva }\end{array}$ & $\begin{array}{l}\text { Avaliar a relação entre o contexto familiar e } \\
\text { a ocorrência do bullying. }\end{array}$ \\
\hline 4 & $\begin{array}{l}\text { Bullying e violência social: vivência de } \\
\text { adolescentes obesos. Denise Bolzan Berlese. } \\
\text { Gustavo Roese Sanfelice. Daiane Bolzan } \\
\text { Berlese. Jacinta Sidegum Renner, } 2017 \text {. }\end{array}$ & $\begin{array}{l}\text { Revista Latino } \\
\text { Americana de } \\
\text { Ciencias Sociales }\end{array}$ & $\begin{array}{l}\text { Desvelar a violência do bullying e violência } \\
\text { social por adolescentes obesos. }\end{array}$ \\
\hline
\end{tabular}

Fonte: Autores, dados da pesquisa

QUADRO 1 - Distribuição dos estudos examinados, segundo o título/autores/ano de publicação, periódicos e contribuição da pesquisa (continuação)

\begin{tabular}{|c|c|c|c|}
\hline n. & Título/Autor(es)/ Ano & Periódico & Contribuição da pesquisa \\
\hline 5 & $\begin{array}{l}\text { Associações entre Bullying Escolar e Conduta } \\
\text { Infracional: Revisão Sistemática de Estudos } \\
\text { Longitudinais. } \\
\text { Jorge Luiz da Silva. } \\
\text { Wanderlei Abadio de Oliveira. Elvio Luciano } \\
\text { Bono. Marina Azôr Dib. Marina Rezende } \\
\text { Bazon. Marta Angélica lossi Silva, } 2016 \text {. }\end{array}$ & $\begin{array}{l}\text { Revista Psicologia: } \\
\text { Teoria e Pesquisa }\end{array}$ & $\begin{array}{l}\text { Investigar a associação entre bullying } \\
\text { escolar e conduta infracional e } \\
\text { criminosa na adolescência e na idade } \\
\text { adulta }\end{array}$ \\
\hline 6 & $\begin{array}{l}\text { A prática de bullying entre escolares } \\
\text { brasileiros e fatores associados: Pesquisa } \\
\text { Nacional de Saúde Escolar 2015. } \\
\text { Flávia Carvalho Malta Mello. Jorge Luiz da } \\
\text { Silva. Wanderlei Abadio de Oliveira. Rogério } \\
\text { Ruscitto do Prado. Deborah Carvalho Malta. } \\
\text { Marta Angélica lossi Silva, 2017. }\end{array}$ & $\begin{array}{l}\text { Revista Ciência \& Saúde } \\
\text { Coletiva }\end{array}$ & $\begin{array}{l}\text { Verificar associações entre a prática } \\
\text { de bullying com variáveis sócio } \\
\text { demográficas, de saúde mental e de } \\
\text { comportamentos de risco em } \\
\text { escolares. }\end{array}$ \\
\hline 7 & $\begin{array}{l}\text { Modos de explicar o bullying: análise } \\
\text { dimensional das concepç̧ôes de } \\
\text { adolescentes. } \\
\text { Wanderlei Abadio de Oliveira. Jorge Luiz da } \\
\text { Silva. lara Falleiros Braga. Claudio Romualdo. } \\
\text { Simona Carla Silvia Caravita. Marta Angélica }\end{array}$ & $\begin{array}{l}\text { Revista Ciência \& Saúde } \\
\text { Coletiva }\end{array}$ & $\begin{array}{l}\text { Identificar as dimensões presentes nas } \\
\text { narrativas dos estudantes brasileiros } \\
\text { sobre o bullying, abordagem que } \\
\text { contribui com a organização dos } \\
\text { programas de cuidado e intervenção } \\
\text { em diferentes áreas. }\end{array}$ \\
\hline
\end{tabular}




\begin{tabular}{|l|l|l|l|}
\hline & lossi Silva, 2018. & & \\
\hline 8 & $\begin{array}{l}\text { Resiliência Educacional e construção do } \\
\text { conhecimento } \\
\text { Carolina Silva Sousa, Antônio Guerreiro, } \\
2014 .\end{array}$ & $\begin{array}{l}\text { Educação } \\
\text { (UFSM) }\end{array}$ & $\begin{array}{l}\text { Demonstrar a importância das } \\
\text { experiências positivas ao gerarem } \\
\text { sentimentos de autoeficácia, de } \\
\text { autoestima ede sucesso acadêmico. }\end{array}$ \\
\hline 9 & $\begin{array}{l}\text { Resposta ao estresse: II. Resiliência e e } \\
\text { vulnerabilidade. Nicole Leite Galvão-Coelho. } \\
\text { Hélderes Peregrino A. Silva. Maria } \\
\text { Bernardete Cordeiro de Sousa, 2015. }\end{array}$ & $\begin{array}{l}\text { Estudos de Psicologia } \\
\text { (Natal) }\end{array}$ & $\begin{array}{l}\text { Pesquisar a interação entre os fatores } \\
\text { genéticos e ambientais que geram os } \\
\text { perfis da resposta psicofisiológica que } \\
\text { caracterizam os fenótipos de } \\
\text { susceptibilidade e resiliência frente aos } \\
\text { estressores e sua relação com uma } \\
\text { patologia mental cada vez mais } \\
\text { presente na sociedade moderna, 0 } \\
\text { transtorno de estresse pós-traumático. }\end{array}$ \\
\hline
\end{tabular}

Fonte: Autores, dados da pesquisa

QUADRO 1 - Distribuição dos estudos examinados, segundo o título/autores/ano de publicação, periódicos e contribuição da pesquisa (continuação)

\begin{tabular}{|c|c|c|c|}
\hline n. & Título/Autor(es)/ Ano & Periódico & Contribuição da pesquisa \\
\hline 10 & $\begin{array}{l}\text { A resiliência no âmbito esportivo: uma } \\
\text { perspectiva } \\
\text { Bioecológica do desenvolvimento humano. } \\
\text { Rita de Cássia da Costa Fontes. Maria } \\
\text { Regina Ferreira Brandão, 2013. }\end{array}$ & $\begin{array}{l}\text { Motriz: Revista de } \\
\text { Educação Física }\end{array}$ & $\begin{array}{l}\text { Investigar na perspectiva do paradigma } \\
\text { biotecnológico a resiliência no contexto do } \\
\text { esporte de alto rendimento. Foram sujeitos } \\
\text { deste estudo sete atletas de basquetebol } \\
\text { que participaram de campeonatos } \\
\text { mundiais e/ou olímpicos. }\end{array}$ \\
\hline 11 & $\begin{array}{l}\text { Resiliencia y juegos cooperativos en el } \\
\text { contexto escolar. Pedro J. Tenório } \\
\text { Maldonado, Máximo Prado Solis, María M. } \\
\text { Cedeño Cortez, } 2017 \text {. }\end{array}$ & $\begin{array}{l}\text { Dominio de Las } \\
\text { Ciências }\end{array}$ & $\begin{array}{l}\text { El presente trabajo tiene como propósito } \\
\text { fundamental describir la importancia del } \\
\text { juego cooperativo como estrategia para el } \\
\text { desarrollo de la resiliencia de los niños en } \\
\text { edad escolar, de vital importancia para } \\
\text { garantizar la adaptación del niño en su } \\
\text { entorno escolar. }\end{array}$ \\
\hline 12 & $\begin{array}{l}\text { Resiliência, suporte social e prática esportiva: } \\
\text { relações e possibilidades de intervenção } \\
\text { social. Paulo Castelar Perim. Nuno Corte- } \\
\text { Real. Cláudia Dias. Melissa Parker. Lidio de } \\
\text { Souza. Antonio Manuel Fonseca, } 2015 \text {. }\end{array}$ & $\begin{array}{l}\text { Psicologia e Saber } \\
\text { Social }\end{array}$ & $\begin{array}{l}\text { Estudar a prática esportiva, a resiliência e } \\
\text { o suporte social junto de } 1052 \text { com idades } \\
\text { entre os } 12 \text { e os } 20 \text { anos }(15,53 \pm 1,68) \text {, } \\
\text { estudantes de escolas públicas brasileiras. }\end{array}$ \\
\hline 13 & $\begin{array}{l}\text { Revisão sistemática da literatura sobre } \\
\text { intervenções antibullying em escolas. Jorge } \\
\text { Luiz da Silva. Wanderlei Abadio de Oliveira. } \\
\text { Flávia Carvalho Malta de Mello. Luciane Sá } \\
\text { de Andrade. Marina Rezende Bazon. Marta } \\
\text { Angélica lossi Silva, 2017. }\end{array}$ & $\begin{array}{l}\text { Revista Ciência \& } \\
\text { Saúde Coletiva. }\end{array}$ & $\begin{array}{l}\text { A revisão sintetiza conhecimentos que } \\
\text { podem ser utilizados para pensar práticas } \\
\text { e programas de intervenção no Brasil, nas } \\
\text { áreas da educação e da saúde, com } \\
\text { caráter multiprofissional. }\end{array}$ \\
\hline
\end{tabular}




\begin{tabular}{|l|l|l|l|}
\hline 14 & $\begin{array}{l}\text { Bullying: verificando a compreensão dos } \\
\text { professores sobre o fenômeno no ambiente } \\
\text { escolar. Maria Teresa Ceron Trevisol. Carlos } \\
\text { Alexandre Campos, 2016. }\end{array}$ & $\begin{array}{l}\text { Psicologia Escolar e } \\
\text { Educacional, }\end{array}$ & $\begin{array}{l}\text { Analisar a compreensão que professores } \\
\text { que atuam na 8a série/90 ano do ensino } \\
\text { fundamental, de um município localizado } \\
\text { na região oeste de Santa Catarina } \\
\text { possuem acerca das razões promotoras do } \\
\text { bullying no ambiente escolar; a natureza } \\
\text { destas razões; como avaliam as } \\
\text { manifestações deste problema e quais as } \\
\text { estratégias utilizadas pela escola para } \\
\text { encaminhar situações de conflito entre os } \\
\text { alunos. }\end{array}$ \\
\hline 15 & $\begin{array}{l}\text { Entre os Muros e as Mídias. O bullying e o } \\
\text { School Shooting numa perspectiva } \\
\text { comunicacional. Flora Daemon, 2015. }\end{array}$ & Revista EPOS & $\begin{array}{l}\text { Refletir sobre crimes deflagrados por } \\
\text { jovens na circunscrição de instituições de } \\
\text { ensino. }\end{array}$ \\
\hline
\end{tabular}

Fonte: Autores, dados da pesquisa

QUADRO 1 - Distribuição dos estudos examinados, segundo o título/autores/ano de publicação, periódicos e contribuição da pesquisa (continuação)

\begin{tabular}{|c|c|c|c|}
\hline $\mathrm{n}$. & Título/Autor(es)/ Ano & Periódico & Contribuição da pesquisa \\
\hline 16 & $\begin{array}{l}\text { Estudo exploratório sobre as concepções e } \\
\text { estratégias de intervenção de professores em } \\
\text { face do bullying escolar. Jorge Luiz da Silva. } \\
\text { Wanderlei Abadio de Oliveira. Marta Angélica } \\
\text { lossi da Silva. Beatriz Oliveira Pereira. Sálua } \\
\text { Cecílio, } 2015 \text {. }\end{array}$ & $\begin{array}{l}\text { Revista Psicologia } \\
\text { Teoria e Prática }\end{array}$ & $\begin{array}{l}\text { Identificar o conhecimento de professores } \\
\text { do } 6^{\circ} \text { ano do ensino fundamental sobre } 0 \\
\text { bullying e as intervenções por eles } \\
\text { desenvolvidas. }\end{array}$ \\
\hline 17 & $\begin{array}{l}\text { Memórias revisitadas: sobre os testemunhos } \\
\text { das vítimas retroativas de bullying no contexto } \\
\text { brasileiro. Juliane Bazzo, } 2016 \text {. }\end{array}$ & Revista DOSSIER & $\begin{array}{l}\text { Este artigo explora a centralidade dos } \\
\text { testemunhos de vítimas no } \\
\text { empreendimento moral do bullying como } \\
\text { gênero de violência difusa no contexto } \\
\text { brasileiro }\end{array}$ \\
\hline 18 & $\begin{array}{l}\text { Bullying e uso de substâncias psicoativas na } \\
\text { adolescência: uma revisão sistemática } \\
\text { Cristina Lessa Horta. Rogério Lessa Horta. } \\
\text { Ariela Mester. Daniele Lindern. João Luís } \\
\text { Almeida Weber. Daniela Centenaro } \\
\text { Levandowski. Carolina Saraiva de Macedo } \\
\text { Lisboa, 2018. }\end{array}$ & $\begin{array}{l}\text { Ciências \& Saúde } \\
\text { Coletiva }\end{array}$ & $\begin{array}{l}\text { Identificar em que medida o envolvimento } \\
\text { em situações de bullying e uso de } \\
\text { substâncias psicoativas na adolescência } \\
\text { se associam, além de verificar se há } \\
\text { diferenças em relação ao papel social do } \\
\text { bullying. }\end{array}$ \\
\hline 19 & $\begin{array}{l}\text { Associações entre Bullying Escolar e } \\
\text { Conduta Infracional: Revisão Sistemática de } \\
\text { Estudos Longitudinais. Jorge Luiz da Silva. } \\
\text { Wanderlei Abadio de Oliveira. Elvio Luciano } \\
\text { Bono, Marina Azôr Dib, Marina Rezende } \\
\text { Bazon, Marta Angélica lossi Silva, 2016. }\end{array}$ & $\begin{array}{l}\text { Psicologia: Teoria e } \\
\text { Pesquisa }\end{array}$ & $\begin{array}{l}\text { Investigar a associação entre bullying } \\
\text { escolar e conduta infracional na } \\
\text { adolescência e criminosa na idade adulta. }\end{array}$ \\
\hline 20 & $\begin{array}{l}\text { Saúde do escolar: uma revisão integrativa } \\
\text { sobre família e bullying. Wanderlei Abadio de } \\
\text { Oliveira. Jorge Luiz da Silva. Julliane Messias } \\
\text { Cordeiro Sampaio. Marta Angélica lossi Silva, } \\
2017 .\end{array}$ & $\begin{array}{l}\text { Revista Ciência \& } \\
\text { Saúde Coletiva }\end{array}$ & $\begin{array}{l}\text { Avaliar a relação entre o contexto familiar e } \\
\text { a ocorrência do bullying. }\end{array}$ \\
\hline
\end{tabular}

Fonte: Autores, dados da pesquisa 


\section{Bullying e Saúde Mental}

O Bullying vem se destacando no contexto escolar nos últimos anos, e demonstrando uma crescente ação desenvolvida pelos estudantes na idade escolar, se tornando uma questão de saúde pública para a sociedade. Mas o que seria essa prática?

Trata-se de um fenômeno caracterizado por comportamentos agressivos intencionais e repetitivos, baseado em relações com desequilíbrio de poder. Inclui-se entre suas formas de manifestação as violências: física (bater ou chutar um colega, por exemplo); verbal (uso de apelidos que humilham, insultos ou xingamentos); e psicológica (amedrontar, perseguir, intimidar ou chantagear, entre outros comportamentos) (MELLO et al, 2017).

Uma grande busca no cotidiano escolar é o engajamento dos alunos nas atividades escolares, este conceito é subdividido em componentes comportamentais, emocionais e cognitivos (Fredricks, 2004, Jimerson; Campos, 2003). Cada componente tem seu papel bem definido, o comportamental tem a ver com seguir as regras e a participação nas atividades escolares, o emocional está relacionado à emoção contida nas relações, e ao sentimento de se pertencer a esse contexto, o engajamento cognitivo relacionado à aprendizagem e seus processos.

A escola, nesse sentido, está diretamente relacionada a seu papel principal, a construção do conhecimento, mas além do seu papel, a escola se torna o primeiro local em que os (as) estudantes se veem vivendo em sociedade, promovendo o aprendizado do convívio.

No cotidiano escolar, o bullying se torna uma forma de violência, na qual cada estudante representa um papel sendo eles: "a) nenhum envolvimento, quando o aluno não participa de qualquer tipo de vitimização ou autoria; b) testemunha, quando o aluno presencia a situação de violência, mas não participa como vítima ou autor; c) vítima, quando o aluno é exclusivamente alvo de bullying; d) autor, quando o aluno comete a agressão, mas não é vítima; e) vítima-autor, quando o aluno pratica bullying, mas também é vítima" (GLEW et al, 2005).

É crescente essa prática no cotidiano escolar, tanto no Brasil como no Mundo. Na Europa, a taxa de jovens em situações de bullying chegou a 27,5\% e 35\%"; na América Latina, um estudo desenvolvido na Nicarágua apontou que dos 3.042 estudantes pesquisados, identificou que uma prevalência de bullying de 50,0\%, sendo que 6,0\% foram identificados como agressores; no Brasil 5,4\% dos estudantes relataram o ter sofrido nas capitais brasileiras em 2009 e 7,2\% em 2012 (MELLO et al, 2017). 
As recentes análises realizadas pela Pesquisa Nacional de Saúde do Escolar (PeNSE, 2015) destacam alguns dados relevantes para a busca de amenizar a prática do Bullying entre estudantes do ensino fundamental e médio. Segundo os dados analisados, o comportamento antissocial associado a problemas emocionais, dificuldade em se adaptar ao ambiente escolar e ao uso de drogas lícitas e ilícitas levam a essa prática, bem como uma relação com a saúde mental e o convívio familiar, sendo destaque os casos que tem relação com os que sofrem violência física e falta de supervisão dos pais.

\section{Caminhos para resiliência ao bullying}

Segundo Souza e Guerreiro (2014) neste milênio a resiliência é um dos principais vetores da educação diante da exposição de altos níveis de estresse causados pelas complexas transformações pelas quais a sociedade está passando nas duas últimas décadas, que geram exigências de intervenção educativa de grande flexibilidade cognitiva, para se adaptar da melhor maneira possível à realidade que circunda.

A American Phycological Association (2013) apud Coelho et al. (2015) define resiliência como o processo de adaptação positiva diante de traumas, adversidades, de situações estressantes, tragédias ou ameaças. Maldonado et al (2017) relata a importância de buscar estratégias educacionais que contribuam para que as crianças desenvolvam comportamento resiliente diante das adversidades.

Fontes e Brandão (2013) afirmam que a resiliência não é um atributo fixo no indivíduo, o mesmo evento negativo pode ser vivenciado de maneira diferente pela mesma pessoa assim como por outros indivíduos. Segundo Souza e Guerreiro (2014), a resiliência pode ser ativada, desenvolvida e otimizada por meio de tarefas, técnicas especiais, experiências, jogos cooperativos, dentre outras.

A escola apresenta condições favoráveis para que a resiliência seja estimulada por possibilitar inúmeras situações e uma gama de experiências como exercício da convivência, o aprendizado, conflitos, entre tantas outras.

Souza e Guerreiro (2014) classificam a resiliência em três tipos: acadêmica, social e a emocional. A resiliência acadêmica segundo esses autores está relacionada à aprendizagem de novas estratégias e na capacidade de resolução de problemas. Já a resiliência social está relacionada ao otimismo, a empatia, aos relacionamentos interpessoais, etc. $E$ a resiliência 
emocional se baseia na capacidade de buscar os aspectos positivos nas experiências, gerando boa autoestima, autoconfiança e capacidade de se adaptar às situações.

Existem três conjuntos de fatores implicados no desenvolvimento de comportamentos resilientes: (a) os atributos e características individuais dos sujeitos, (b) aspectos relacionados às famílias, e (c) características dos ambientes sociais com os quais o sujeito interage. (PERIM et al, 2015, p. 211, 212.).

Maldonado et al (2017) descreve que os Jogos Cooperativos são ferramentas eficazes no desenvolvimento da resiliência. Os jogos cooperativos proporcionam a oportunidade de expressar afeto e apreço, através de palavras, gestos, abraços, entre outros. Além disso, no jogo 0 professor se concentra nos aspectos positivos do aluno contribuindo para melhora da autoestima.

Dessa forma, uma das principais tarefas do professor é encontrar e fortalecer as qualidades positivas dos alunos que Ihes permitirão superar a dificuldades, ter sucesso e preparar-se para uma integração social adequada e criativa (MALDONADO et al, 2017).

Souza e Guerreiro (2014) corroboram com esse autor, ressaltando a relevância da valorização e reconhecimento dos diferentes saberes dos discentes, destacando os aspectos positivos, bem como estimulando a cooperação, os relacionamentos interpessoais, o apoio mútuo desenvolvendo as competências sociais e o sentimento de pertencimento ao grupo. Em interface, contribui para ajudar alunos a lidarem com as mudanças e com as adaptações a novas situações de aprendizagem aprimorando a resiliência.

\section{Propostas de intervenção ao bullying}

Segundo Silva et al (2017), o bullying é considerado um problema de saúde pública cujas consequências para a sociedade e comunidade escolar podem ser relevantes gerando impactos negativos na saúde mental, física, social e emocional. Silva et al (2016) alerta que uma das consequências graves seria indícios de sua contribuição para a conduta infracional e criminal. Horta (2018) relata que jovens envolvidos com essa prática como agressores ou vítimas são mais vulneráveis ao uso de substâncias psicoativas em comparação àqueles não envolvidos.

Diante deste cenário preocupante, no qual as instituições educacionais vêm se tornando ambientes pouco seguros, de relações hostis, de intimidação, gerando angústia, sofrimento e 
medo, é preciso buscar estratégias de intervenção e prevenção que contribuam para a cultura de paz.

Segundo Silva (2015), vêm sendo mais eficazes as intervenções que abrangem os variados contextos, visto que esse é um fenômeno multifacetado. Daemon (2015) relata que no bullying o olhar do outro cria a imagem de si, ou seja, é uma dinâmica social voltada para o olhar alheio.

Talvez o ponto de partida seja diagnosticar as causas desse fenômeno no intuito de criar propostas que possam reduzir seus efeitos e ocorrência. Silva et al (2015) afirma que é importante compreender a dinâmica do fenômeno bullying para gerar programas de intervenção. Trevisol e Campos (2016) fazem referência aos diversos estudos descritos por Fante e Pedra (2008) sobre as prováveis causas, levando em consideração circunstâncias: familiares, culturais, sociais, afetivas e emocionais.

Outra questão enfatizada Trevisol e Campos (2016) é o alto nível de competição presente na escola e no ambiente familiar, gerando individualismo e relações interpessoais com pouca empatia, ou seja, a educação não tem como base as virtudes humanas o que pode gerar e contribuir para a ocorrência dessa prática.

\footnotetext{
A educação da criança na família está muito centrada na competitividade e na vitória a qualquer preço e não está a ser direcionada para a aquisição de competências graduais, de acordo com a idade e adquiridas pela cooperação e solidariedade. E a escola, em vez de corrigir este enviesamento vai reforçá-lo de inúmeras formas contribuindo para o clima de indiferença que se está a observar (PEREIRA; SILVA, NUNES, 2009, p. 465 apud TREVISOL e CAMPOS, 2016).
}

Em síntese esta revisão integrativa alerta que o bullying é um problema sério, de saúde pública que vem causando: o aumento da suscetibilidade de jovens ao uso de substâncias psicoativas, ingresso na criminalidade, doenças psíquicas, dificuldade de aprendizagem, evasão escolar entre outras consequências com menor ou maior gravidade. Diante deste cenário preocupante é preciso buscar estratégias de intervenção e prevenção que contribuam para a cultura de paz.

Maldonado et al (2017) relata a importância de buscar estratégias educacionais que contribuam para que as crianças desenvolvam comportamento resiliente diante das adversidades. Este autor descreve que os Jogos Cooperativos são ferramentas eficazes no desenvolvimento da resiliência, pois proporcionam a oportunidade de expressar afeto e apreço, através de palavras, gestos, abraços, entre outros. Além disso, no jogo o professor se concentra nos aspectos positivos do aluno contribuindo para melhora da autoestima. 
Sendo assim, além do combate e das medidas preventivas do fenômeno bullying, talvez seja mais um antídoto investir no desenvolvimento da resiliência ao bullying. Diante do exposto esta revisão integrativa do fenômeno do bullying e da resiliência serviu de base teórica para a criação do aplicativo (Jogo Cooperativo) Humanizar, cujo propósito é contribuir para a resiliência ao bullying.

\section{Proposta de Aplicativo como forma de Resiliência ao Bullying}

Orlick (1978) afirma que todos os criminosos já foram crianças que brincavam e frequentavam a escola, ressalta a importância de ensinar valores humanos para as crianças para que valorizem as outras pessoas, cultivando habilidades humanas para que as habilidades de desempenho sejam bem direcionadas. Oliveira et al (2017) corrobora com Orlick ao relatar a responsabilidade da escola de criar um ambiente que contribua para o desenvolvimento da aprendizagem e da autoestima, baseado no respeito por todos.

Maturana e Rezepka (2000) afirma que a agressividade é de origem cultural. As crianças nascem sabendo amar e as conversações da cultura em que vivem é que as fazem desaprenderem o sentimento de amar. As consequências são que se comportam de forma agressiva mesmo sendo geneticamente amorosas. Portanto, o jogo cooperativo possui uma estrutura que pode contribuir para que a criança desperte para se tornar um adulto humanista, pois promove experiências ricas de encontro profundo consigo mesmo e com o outro. É um brincar de se acolher nos braços do sentimento de solidariedade, no movimento de construir, juntos, o bem comum. "Jogar e viver é uma oportunidade criativa de encontrar: Com a gente mesmo, Com os outros, Com o todo" (BROTTO, 1997, p.35).

Segundo Orlick (2010), a mudança positiva é possível e começa pela valorização e olhar positivo de si mesmo, respeito e apreciação pelo outro e em vislumbrar possibilidades de um mundo melhor. No comprometimento em ajudar a si próprio, aos outros a se tornarem mais positivos, fazendo a diferença positiva na própria vida, na dos outros e no planeta.

Com o propósito de contribuir para uma educação para a Condição Humana, foi criado um aplicativo, com o nome de Humanizar, baseado no método de Habilidades Positivas, nos Jogos Cooperativos do Dr. Terry Orlick e na Ética do Cuidado de Heidegger. O objetivo geral deste jogo é contribuir para uma vida mais positiva. Os objetivos específicos são: aumentar a resiliência ao bullying, cultivar virtudes e propagar a Ética do Cuidado. 
O aplicativo foi desenvolvido no Mit App Inventor, uma ferramenta de programação baseada em blocos para dispositivos Android. Inicialmente desenvolvido pelo professor Hal Abeson e uma equipe do Google Education. App Inventor funciona como um Web Service administrado por membros do MIT's Center for Mobile Learning. MIT App Inventor possui uma comunidade mundial de quase 3 milhões de usuários, representando 195 países em todo 0 mundo. Mais de 100 mil usuários ativos semanalmente e que já construíram mais de 7 milhões de aplicativos para Android.

O App Inventor é uma ferramenta aberta que permite a programação e criação de aplicativos acessível a uma grande variedade de públicos. O programa é desenvolvido em duas telas distintas, uma denominada interface de criação do design e a segunda um editor de blocos onde a programação de troca de telas, botões e funções são programadas.

0 aplicativo (jogo cooperativo) é composto de seis telas, como mostrado na Figura 1:1 regras do jogo; 2 - Si mesmo; 3 - Lar; 4 - Escola, 5 - Planeta, 6 - Integração. 0 objetivo do jogo é humanizar: a si mesmo, o lar, a escola e o planeta. Neste intuito o jogo propõe missões especiais através de áudios e convida para criar um plano estratégico de realização de cada missão sugerida durante 21 dias consecutivos.

A primeira tela, Humanizar a si mesmo, é composta de quatro missões que foram gravadas em áudios dos seguintes temas: Cuidado de $\mathrm{Si}$, Relaxamento, Foco Positivo e Auto Apreço. Na segunda tela, Humanizar o Lar, os temas são: gentileza, cooperação, foco positivo, apreço e gratidão. Na terceira tela Humanizar a Escola: Afetividade, Cooperação, Propague Virtudes e Apreciação. Na quarta tela, Humanizar o planeta: Guardiões da Natureza, Pratique os 5 Rs, Ações Solidárias e Seja um agente de Inclusão.

Cada tela é composta por quatro missões, após completar o ciclo o participante deverá selecionar a casa da âncora no positivo, onde receberá instruções para ancorar os hábitos vivenciados na tela. Para concluir a etapa do jogo e passar para uma nova tela, o jogador deverá selecionar a casa da onda do amor, onde será convidado para propagar a humanização. 0 mesmo acontecerá nas telas seguintes até vencer o jogo chegando à tela da integração, onde uma borboleta alçará voo. 

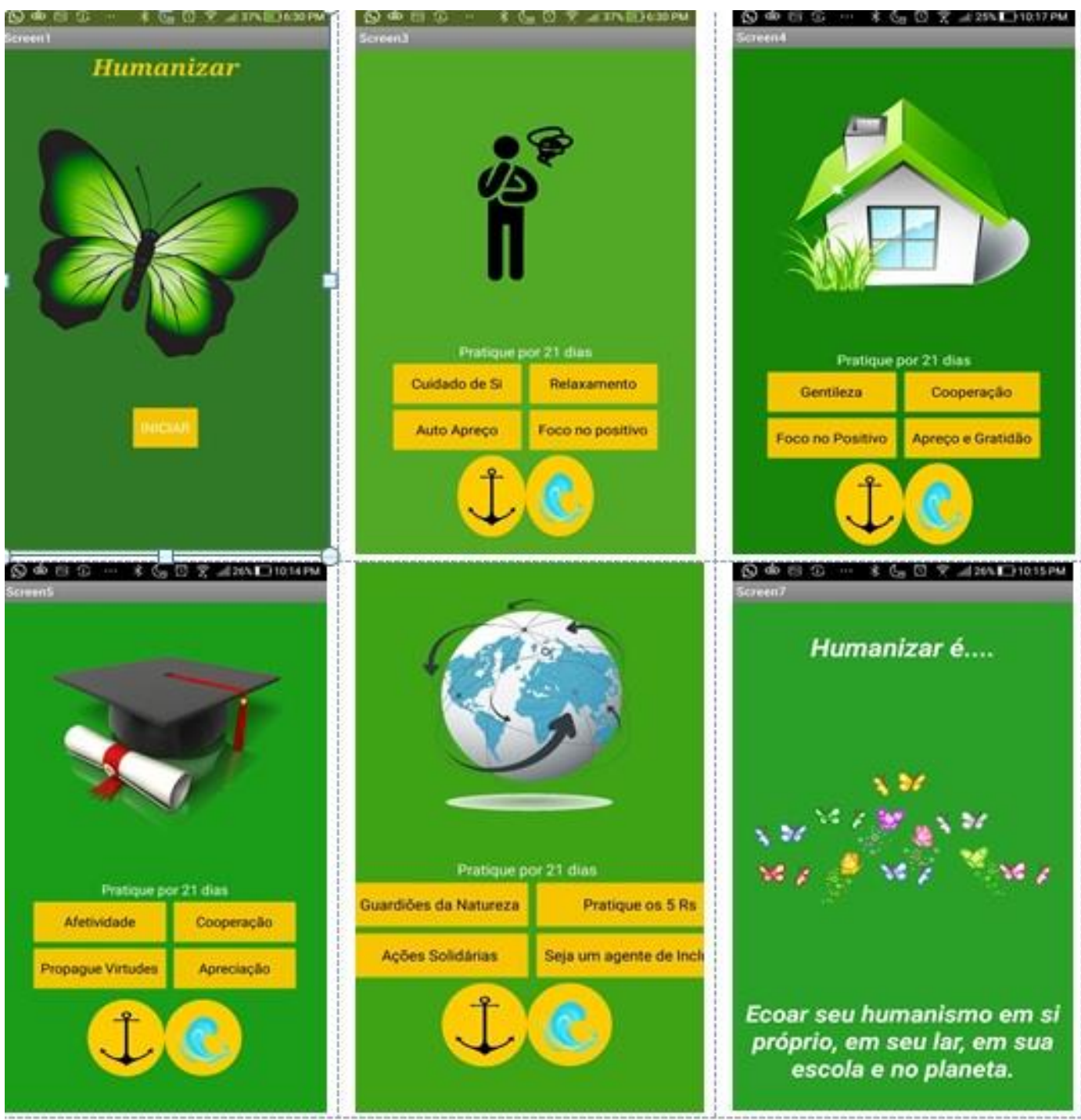

FIGURA 1 - As seis telas do aplicativo Humanizar

Fonte: Autores

O APP Humanizar é uma proposta que se encontra em fase de aprimoramento, necessitando passar pela fase de testes para posteriormente ser disponibilizado gratuitamente no Google Play Store, uma loja oficial de aplicativos para smartphones e tablets com sistema operacional Android.

\section{CONSIDERAÇÕES FINAIS}

O presente trabalho teve como objetivo estudar o fenômeno do bullying e da resiliência e propor a criação de um aplicativo (jogo cooperativo) que visa aumentar a resiliência ao bullying. 
A pesquisa revelou que a resiliência é um dos principais vetores da educação e que pode ser ativada, desenvolvida e otimizada através de tarefas, técnicas especiais, experiências, jogos cooperativos, dentre outras.

Os resultados revelaram que os jogos cooperativos podem ser ferramentas eficazes no desenvolvimento da resiliência, como intervenção do bullying e que podem contribuir para que a criança desperte para se tornar um adulto humanista.

Sendo assim, este artigo serviu de base teórica para a criação do aplicativo Humanizar (Jogo Cooperativo), cujo propósito é contribuir para a resiliência ao bullying e contribuir para que Educação atinja o objetivo de educar para a condição humana.

\section{REFERÊNCIAS}

BAZZO, Juliane. Memórias revisitadas: sobre os testemunhos das vítimas retroativas de bullying no contexto brasileiro. Revista de Estudios Sociales, n. 59, p. 56-67, 2017. Disponível em: $<$ http://www.scielo.org.co/scielo.php?pid=S0123885X2017000100056\&script=sci_abstract\&tIng=pt>. Acesso em: 25 abr 2019.

BOLZAN, Denise Berlese; ROESE, Gustavo Sanfelice; BOLZAN, Daiane Berlese; SIDEGUM, Jacinta Renner. Bullying e violência social: vivência de adolescentes. Revista Latino Americana Ciencias Sociales, v.15, n.1, p.491-503, 2017. Disponível em: $<$ http://www.scielo.org.co/scielo.php?pid=S1692715X2017000100032\&script=sci_abstract\&tlng=pt>. Acesso em: 25 abr 2019.

BRASIL: Lei N0 13.185, de 6 de Novembro de 2015. Institui o Programa de Combate à Intimidação Sistemática (Bullying). Disponível em: <http://www.planalto.gov.br/ccivil_03/ Ato2015-2018/2015/Lei/L13185.htm>. Acesso em: 05 mai 2019.

BRASIL: Lei $\mathrm{n}^{0}$ 13.663, de 14 de maio de 2018. Dispõe sobre promoção de medidas de conscientização, de prevenção e de combate a todos os tipos de violência nos estabelecimentos de ensino. Disponível em: <http://www.planalto.gov.br/ccivil_03/_ato20152018/2018/Lei/L13663.htm>. Acesso em: 05 maio 2019.

BROTTO, Fábio Otuzzi. Jogos cooperativos: "se o importante é competir, o fundamental é cooperar". [s.l.]: Ed. Re-Novada/Projeto Cooperação, 1997.

CAVALCANTI, Jaqueline Gomes; COUTINHO, Maria da Penha de Lima; PINTO, Adriele Vieira de Lima; SILVA, Carla Costa; BÚ, Emerson do Araújo. Vitimização e Percepção do Bullying: Relação com a Sintomatologia Depressiva de Adolescentes. Revista de Psicologia da IMED, v.10, n.1, p.140-159, 2018. Disponível em:

<https://seer.imed.edu.br/index.php/revistapsico/article/view/2725/1776>. Acesso em: 25 abr 2019.

DAEMON, Flora. Entre os muros e as mídias: o bullying e o school shooting numa perspectiva comunicacional. Revista EPOS, v. 6, n. 2, p. 06-26, 2015. Disponível em: 
$<$ http://pepsic.bvsalud.org/scielo.php?script=sci_abstract\&pid=S2178700X2015000200002\&Ing=pt\&nrm=iso>. Acesso em: 25 abr 2019.

FONTES, Rita de Cássia da Costa; BRANDÃO, Maria Regina Fereira. A resiliência no âmbito esportivo: uma perspectiva bioecológica do desenvolvimento humano. Motriz: Revista de Educação Física, v.19, n.1, p.151-159, 2013. Disponível em:

<http://www.scielo.br/pdf/motriz/v19n1/a15v19n1.pdf>. Acesso em: 25 abr 2019.

GALVÃO- COELHO, Nicole Leite; SILVA DA, Hélderes Alves Peregrino; SOUSA, Maria Bernadete Cordeiro de. Resposta ao estresse: II. Resiliência e vulnerabilidade. Estudos de Psicologia, v.20, n.2, p.72-81, 2015. Disponível em: <http://www.scielo.br/scielo.php?pid=S1413-294X2015000200072\&script=sci_abstract\&tlng=pt>. Acesso em: 25 abr 2019.

HORTA, Cristina Lessa; HORTA, Rogério Lessa; MESTER, Ariela; LINDERN, Daniele; LISBOA, Carolina Saraiva de Macedo; WEBER, João Luís Almeida; LEVANDOWSKI, Daniela Centenaro. Bullying e uso de substâncias psicoativas na adolescência: uma revisão sistemática. Ciência \& Saúde Coletiva, v. 23, n. 1, p. 123 - 140, 2018. Disponível em:

<https://www.scielosp.org/article/ssm/content/raw/?resource_ssm_path=/media/assets/csc/v23n1 |1413-8123-csc-23-01-0123.pdf>. Acesso em: 25 abr 2019.

LIRA, Lidianne Leite. Bullying: percepções dos estudantes em uma escola pública de Diversitas Journal: Brasília, v. 4, n. 1, p. 172-178, 2019. Disponível em: <http://periodicos.ifal.edu.br/diversitas_journal/article/view/709>. Acesso em: 25 abr 2019.

MALDONADO, José Pedro; TENORIO, Máximo Prado-Solis; CEDEÑO-CORTEZ, Maria. Resiliencia y juegos cooperativos en el contexto escolar. Dominio de las Ciencias, n. Extra 3, p.456-69, 2017. Disponível em:

<http://dominiodelasciencias.com/ojs/index.php/es/article/view/652>. Acesso em: 25 abr 2019.

MATURANA, Humberto; REZEPKA, Sima Nisis Formação humana e capacitação. Petrópolis: Vozes, 2000.

MELLO, Flávia Malta Carvalho; SILVA, Jorge Luís da; OLIVEIRA, Wanderlei Abadio de; PRADO, Rogério Ruscitto do; MALTA, Deborah Carvalho; SILVA, Angélica lossi. A prática de bullying entre escolares brasileiros e fatores associados, Pesquisa Nacional de Saúde do Escolar, 2015.

Revista Ciência e Saúde Coletiva, v.22, n.9, p.2939 - 2948, 2017. Disponível em: < http://www.scielo.br/pdf/csc/v22n9/1413-8123-csc-22-09-2939.pdf>. Acesso em: 25 abr 2019.

MIRANDA, Marcelo Henrique Goncalves de; LIMA, Larissa Suellen Gomes Andrade de. A prática pedagógica dos direitos humanos: marcadores sociais da diferença e o combate ao bullying.

Momento: diálogos em educação, v. 28, n. 1, p. 328-348, 2019. Disponível em: < https://periodicos.furg.br/momento/article/view/7847/5797>. Acesso em: 05 mai 2019.

OLIVEIRA, Francisco Nazareno. Bullying e o cyberbullying na escola. Revista de Ciências Humanas, v. 19, n. 03, p. 83-91, 2018. Disponível em:

<http://revistas.fw.uri.br/index.php/revistadech/article/view/3235>. Acesso em: 25 abr 2019.

OLIVEIRA, Wanderlei Abadio de; SILVA, Jorge Luís da; BRAGA, lara Falleiro; ROMUALDO, Claudio; CARAVITASILA, Simone Carla; SILVA, Marta Angélica lossi. Modos de explicar 0 
bullying: análise dimensional das concepções de adolescentes. Revista Ciência e Saúde Coletiva, v.23, n.3, p.751-761, 2018. Disponível em: <http://www.scielo.br/pdf/csc/v23n3/14138123-csc-23-03-0751.pdf >. Acesso em: 25 abr 2019.

OLIVEIRA, Wanderlei Abadio de; SILVA, Jorge Luís da; SAMPAIO, Julliane; CORDEIRO, Messias; SILVA, Marta Angélica lossi. Saúde do escolar: uma revisão integrativa sobre família e bullying. Revista Ciência \& Saúde Coletiva, v.22, n.5, p.1553-1564, 2017. Disponível em:< http://www.scielo.br/scielo.php?pid=S1413-81232017002501553\&script=sci_abstract\&tlng=pt>. Acesso em: 25 abr 2019.

ORLICK, Terry. Vencendo a Competição. São Paulo: Círculo do livro,1978.

ORLICK, Terry. Positive Living Skills: Joy and Focus for Everyone. General Store Publishing House, 2010.

PERIM, Paulo Castelar; CORTE-REAL, Nuno; DIAS, Cláudia; PARKER, Melissa; SOUZA, Lidio de; FONSECA, Antonio Manuel. Resiliência, suporte social e prática esportiva: relações e possibilidades de intervenção social. Psicologia e Saber Social, v.4, n.2, p.207-23, 2015. Disponível em: < https://www.e-publicacoes.uerj.br/index.php/psi-sabersocial/article/view/15194 >. Acesso em: 25 abr 2019.

SILVA, Fábio Luiz da Silva; MUZARDO, Fabiane Tais; ZAMARIAM, Julho; SILVA, Fabio Alexandre da. As violências no ambiente escolar: o bullying na percepção de professores e alunos. Cadernos da Pedagogia, v. 12, n. 23, p. 34-42, 2018. Disponível em: < http://www.cadernosdapedagogia.ufscar.br/index.php/cp/article/view/1176/417>. Acesso em 05 mai 2019.

SILVA, Jorge Luiz da; OLIVEIRA, Wanderlei Abadio de; BONO, Luciano Elvio; DIB, Marina Azôr. BAZON, Marina Resende. SILVA, Marta Angélica lossi. Associações entre Bullying Escolar e Conduta Infracional: Revisão Sistemática de Estudos Longitudinais. Revista Psicologia: Teoria e Pesquisa, v.32, n.1, p.81-90, 2016. Disponível em: < http://www.scielo.br/pdf/ptp/v32n1/18063446-ptp-32-01-00081.pdf>. Acesso em: 25 abr 2019.

SILVA, Jorge Luiz da; OLIVEIRA, Wanderlei Abadio de; MELLO, Flávia de Malta Carvalho; ANDRADE, Luciane de Sá. BAZON, Marina Rezende; SILVA, Marta Angélica lossi. Revisão sistemática da literatura sobre intervenções antibullying em escolas. Ciência \& Saúde Coletiva, v. 22, n. 7, p. 2329-2340, 2017. Disponível em:

$<$ http://www.cienciaesaudecoletiva.com.br/artigos/revisao-sistematica-da-literatura-sobreintervencoes-antibullying-em-escolas/15490?id=15490>. Acesso em: 25 abr 2019.

SILVA, Jorge Luiz da; OLIVEIRA, Wanderlei Abadio de; SILVA, Marta Angélica lossi; PEREIRA, Beatriz Oliveira; CECÍLIO, Sálua. Estudo exploratório sobre as concepções e estratégias de intervenção de professores em face do bullying escolar. Psicologia: teoria e prática, v. 17, n. 3 , p. 189-199, 2015. Disponível em: < http://editorarevistas.mackenzie.br/index.php/ptp/article/view/6123/5538>. Acesso em 25 abr 2019.

SILVA, Viviane Heck; OSIECKI, Ana Claudia. Influência do gênero no bullying escolar. Vitrine de Produção Acadêmica, v. 6, n. 1, p. 175-190, 2018. 
Disponível em:

<http://www.vitrineacademica.dombosco.sebsa.com.br/index.php/vitrine/article/view/528/537>.

Acesso em: 05 mai 2019.

SILVA, Fábio Luiz da Silva; MUZARDO, Fabiane Tais; ZAMARIAM, Julho; SILVA, Fabio

Alexandre da. As violências no ambiente escolar: o bullying na percepção de professores e alunos. Cadernos da Pedagogia, v. 12, n. 23, p. 34-42, 2018. Disponível em: <

http://www.cadernosdapedagogia.ufscar.br/index.php/cp/article/view/1176/417>. Acesso em 05 mai 2019.

SOUSA, Carolina Silva; GUERREIRO, António. Resiliência educacional e construção do conhecimento. Educação (UFSM), v.39, n.3, p.567-76, 2014. Disponível em: <https://periodicos.ufsm.br/index.php/reveducacao/article/view/14343>. Acesso em: 15 abr 2019.

SOUZA, Luciana Martins de; FIGUEIREDO, Guilherme Gitahy de. O aluno é o "lobo do homem"? O bullying como reprodução das relações de dominação social na escola. SOMANLU: Revista de Estudos Amazônicos, ano 18, n. 1, p, 68-81, 2018. Disponível em: <

http://periodicos.ufam.edu.br/somanlu/article/view/5080>. Acesso em: 05 mai 2019.

SOUZA, Marcela Tavares de; SILVA, Michelly Dias da; CARVALHO, Rachel de. Revisão integrativa: o que é e como fazer. Einstein, v. 8, n. 1, p. 102-106, 2010. Disponível em: < http://astresmetodologias.com/material/O_que_e_RIL.pdf>. Acesso em 08 abr 2019.

TREVISOL, Maria Tereza Ceron; CAMPOS, Carlos Alexandre. Bullying: verificando a compreensão dos professores sobre o fenômeno no ambiente escolar. Psicologia Escolar e

Educacional, $\quad$ v. $20, \quad$ n. 2, p. 275-284, 2016. Disponível em: <http://www.scielo.br/pdf/pee/v20n2/2175-3539-pee-20-02-00275.pdf>. Acesso em 25 abril 2019.

VALLE, Jéssica Elena. PEREIRA- STELKO, Ana Carina. SÁ, Lucas Guimarães Cardoso.

WILLIAMS, Lúcia Cavalcanti de Albuquerque. Bullying, vitimização por funcionários e depressão: Relações com o engajamento emocional escolar. Revista Brasileira de Psicologia Escolar e Educacional, v.19, n.3, p.463-473, 2015. Disponível em:

<http://www.scielo.br/pdf/pee/v19n3/2175-3539-pee-19-03-00463.pdf>. Acesso em 25 abril 2019. 